\title{
Synthesis of palladium-carbon nanotube-metal organic framework composite and its application as electrocatalyst for hydrogen production
}

\author{
Zahra Ghiamaty $^{1} \cdot$ Ali Ghaffarinejad ${ }^{1,2} \cdot$ Mojtaba Faryadras $^{3} \cdot$ Abbas Abdolmaleki $^{4}$. \\ Hojjat Kazemi ${ }^{5}$
}

Received: 4 June 2016/ Accepted: 5 August 2016/Published online: 11 August 2016

(c) The Author(s) 2016. This article is published with open access at Springerlink.com

\begin{abstract}
There are very rare reports on using metal-organic framework (MOF) catalysts for electrochemical hydrogen production. In this study, a composite of palladium, single-walled carbon nanotube (SWCNT) and MOF199 (Pd/SWCNTs@MOF-199) was synthesized by hydrothermal method, and its application as electrocatalyst in carbon paste electrode (CPE) structure for hydrogen production was studied. Scanning electron microscopy, $\mathrm{X}$-ray diffraction, Brunauer-Emmett-Teller and thermal gravimetric analysis were used to characterize $\mathrm{Pd} /$ SWCNTs@MOF-199 catalyst. The performance of the proposed modified CPE for electrochemical hydrogen production was studied by cyclic voltammetry, linear sweep voltammetry, electrochemical impedance spectroscopy and chronoamperometry techniques. The effect of solution $\mathrm{pH}$ and the amount of binder and catalyst in the paste composition were investigated. The results showed
\end{abstract}

Electronic supplementary material The online version of this article (doi:10.1007/s40097-016-0203-4) contains supplementary material, which is available to authorized users.

Ali Ghaffarinejad

Ghaffarinejad@iust.ac.ir

1 Research Laboratory of Real Samples Analysis, Faculty of Chemistry, Iran University of Science and Technology, Tehran 1684613114, Iran

2 Electroanalytical Chemistry Research Centre, Iran University of Science and Technology, Tehran 1684613114, Iran

3 Faculty of Chemistry, Iran University of Science and Technology, Tehran 1684613114, Iran

4 Department of Chemistry, Malek-Ashtar University of Technology, Tehran, P.O. Box 16765-34543, Iran

5 Research Institute of Petroleum Industry, Tehran 1485733111, Iran that the CPE modified with Pd/SWCNTs@MOF-199 reveals better catalytic characteristics such as highest catalytic activity and lowest onset potential compared to $\mathrm{CPE}$ and CPE modified with MOF-199 for hydrogen production in aqueous solution.

Keywords Metal organic framework composite · Electrochemical hydrogen production - Carbon paste electrode $\cdot$ Electrocatalyst

\section{Introduction}

Today, fossil fuels with disadvantages such as limited resources, warming up the earth and the environmental pollution are known as the main energy sources. Many efforts are being made to use other energy sources instead of fossil fuels which do not have disadvantages mentioned above. Nuclear energy, which its sources are limited, and working with it requires training of skilled manpower and use of advanced systems for protection against radioactive waste, will not be able to supply the required energy of the world.

Nowadays, hydrogen as a raw material is used in different industries [1]. Hydrogen produces high amount of energy with almost no pollution. It is a renewable energy carrier, and its resource is infinite [2]. An energy carrier can change energy to the forms which are usable to consumers. Although, renewable energy sources such as sun and wind cannot provide energy all the time, they could produce electric energy and hydrogen, which can be stored and transported until they are needed.

Several ways such as hydrolysis [3], thermal catalysis and thermochemical $[4,5]$, photocatalysis [6, 7], photoelectrocatalysis [8], steam reforming [9], gasification [10] 
and electrolysis $[5,11]$ are used to produce hydrogen. Although in the electrochemical studies platinum (Pt) is known as an excellent electrode for hydrogen generation, but because of limitation of its resource and its expensive price we should look for a suitable alternative to Pt [12]. There are several reports which have attempted to reduce the amount of loaded $\mathrm{Pt}$ in the electrode body [13] or replace it with another catalyst [14-16].

MOFs are synthesis by linking inorganic and organic units by strong bonds that lead to combined properties of organic and inorganic porous materials [17-19]. Among the wide range of available catalysts, MOFs have recently received noticeable attention owing to their characteristics such as porosity, specific surface area and adjustable pore size [20, 21]. Related to hydrogen energy, MOFs have been mostly used for hydrogen storage [22-25] and there are some reports in hydrogen generation area with photocatalytic method [26-28], and a few reports for electrochemical hydrogen generation [29-31].

In this study, a composite of MOF-199 with Pd and single-walled carbon nanotube (SWCNT) was prepared (Pd/SWCNTs@MOF-199), and was applied for electrochemical hydrogen generation. Structure and morphology of the composite were characterized by various techniques, and its electrochemical hydrogen generation performance was compared with MOF-199 in CPE.

\section{Experimental}

\section{Apparatus and software}

The electrochemical impedance measurements were performed with an Autolab potentiostat/galvanostat (PGSTAT30) equipped with FRA board, also all other electrochemical studies were done with a $\mu$-Autolab type II potentiostat/galvanostat that the software for both of them was Nova version 1.7.8. A three electrode cell containing, Pt rod as the counter electrode, bare or modified CPE as working electrode and $\mathrm{Ag} / \mathrm{AgCl}(3 \mathrm{M} \mathrm{KCl})$ as the reference electrode was used. In this paper, for easier comparison with other reports all potential values are reported vs. reversible hydrogen electrode (RHE). Teflon cylinder ( $3.0 \mathrm{~mm}$ i.d.) that was firmly packed with carbon paste was used as the body of the working electrode. To creation electrical connect a stainless steel rod inserted into the carbon paste. All electrochemical experiments were done at room temperature, also before every experiment the electrolyte solution was deaerated with high purity nitrogen gas for at least $10 \mathrm{~min}$.

The MOF structure was investigated between $5^{\circ} \leq 2 \theta \leq 90^{\circ}$ with X-ray diffraction (XRD) instrument model of PHILIPS 1830 with a $\mathrm{Cu}(\mathrm{K} \alpha)$ radiation source $(\lambda=1.5418 \AA)$.

The catalyst morphology and its elemental analysis was investigated with a scanning electron microscopy (SEM) (VEGAIITESCAN-XMU) equipped with energy dispersive $\mathrm{X}$-ray analysis (EDX).

Thermogravimetric analysis (TGA) was used to determine the thermal behaviour of MOF-199 and $\mathrm{Pd} /$ SWCNT@MOF-199 using SHIMADZU, TG-50/DTA-50. The measurements were conducted at $10{ }^{\circ} \mathrm{C} \mathrm{min}{ }^{-1}$ from room temperature.

Nitrogen adsorption-desorption isotherms were measured at $77 \mathrm{~K}$ by a BET instrument model of $\mathrm{ASAP}^{\mathrm{TM}}$ micromeritics 2020 .

\section{Materials and solutions}

Graphite fine powder (extra pure with P.S. $<50 \mu \mathrm{m}$ ), paraffin oil (spectroscopic grade, Uvasol ${ }^{\circledR}$ ), $\mathrm{H}_{3} \mathrm{PO}_{4}(85 \%)$, $\mathrm{KCl}(99.5 \%), \mathrm{H}_{2} \mathrm{SO}_{4}(98 \%), \mathrm{Cu}\left(\mathrm{NO}_{3}\right)_{2} \cdot 3 \mathrm{H}_{2} \mathrm{O}(99.5 \%)$, benzene-1,3,5-tricarboxylic acid $\left(\mathrm{H}_{3} \mathrm{BTC}, 95 \%\right), \mathrm{PdCl}_{2}$ (59\% Pd basis) and ethanol (96\%) were obtained from Merck and were used without furture purifications. The single walled carbon nanotube $(>95 \%)$ was purchased from Sigma and was treated with nitric acid $(5 \mathrm{M})$ for 15 min. After treatment, the SWCNTs were filtered and washed with deionised water to remove any remained nitric acid and impurities. All aqueous solutions were prepared with deionized water.

\section{MOF-199 synthesis}

MOF-199 was synthesized as previously reported [32]. In brief, $2.3268 \mathrm{~g}$ of $\mathrm{Cu}\left(\mathrm{NO}_{3}\right)_{2} \cdot 3 \mathrm{H}_{2} \mathrm{O}$ was dissolved in $24 \mathrm{~mL}$ deionized water, and $1.4140 \mathrm{~g} \mathrm{H}_{3} \mathrm{BTC}$ was dissolved in $24 \mathrm{~mL}$ ethanol. Both solutions were mixed with magnetic stirrer and then put into a $100 \mathrm{~mL}$ stainless steel autoclave at $120{ }^{\circ} \mathrm{C}$ for $12 \mathrm{~h}$. The product was washed with ethanol and water, and then put at $70{ }^{\circ} \mathrm{C}$ for $30 \mathrm{~min}$, and after this the resultant was put at $150{ }^{\circ} \mathrm{C}$ for $30 \mathrm{~min}$. The final product was MOF-199.

\section{Pd/SWCNT synthesis}

$\mathrm{PdCl}_{2}(0.16 \mathrm{~g})$ was dissolved in $5 \mathrm{~mL}$ ethanol, $0.10 \mathrm{~g}$ of treated SWCNT was added to the proposed solution, and was dispersed using ultrasonic bath. After dispersion, during stirring of the mixture, $1 \mathrm{~mL}$ hydrazine was added dropwise under nitrogen atmosphere. Then the $\mathrm{pH}$ was adjusted to 9 with $1 \mathrm{M} \mathrm{NaOH}$ solution. For complete reduction of palladium the mixture was stirred on the magnetic stirrer for $2 \mathrm{~h}$ at $100{ }^{\circ} \mathrm{C}$. Finally, the precipitate 
was filtered and washed with deionized water and then dried in oven at $100{ }^{\circ} \mathrm{C}$ for $4 \mathrm{~h}$. This product is called $\mathrm{Pd} /$ SWCNT.

\section{Synthesis of Pd/SWCNTs@ MOF-199 nanocomposite}

Pd/SWCNTs@MOF-199 nanocomposite was prepared according to a previously reported procedure for synthesis of SWCNT@MOF-5 [33]. For this purpose, $2.320 \mathrm{~g}$ of $\mathrm{Cu}\left(\mathrm{NO}_{3}\right)_{2} \cdot 3 \mathrm{H}_{2} \mathrm{O}$ was dissolved in $24 \mathrm{~mL}$ deionized water, and $1.414 \mathrm{~g} \mathrm{H}_{3}$ BTC was dissolved in $24 \mathrm{~mL}$ ethanol. Both solutions were mixed with magnetic stirrer for $20 \mathrm{~min}$. Then $0.100 \mathrm{~g}$ of Pd/SWCNTs was added to the obtained solution, and was stirred for about $24 \mathrm{~h}$ at room temperature. The resultant mixture was transferred to autoclave and heated at $120{ }^{\circ} \mathrm{C}$ for $12 \mathrm{~h}$. The precipitate was filtered, and washed with boiling deionized water and acetone. The washed precipitate was dried in vacuum oven at $100{ }^{\circ} \mathrm{C}$ for $4 \mathrm{~h}$. The final product (Pd/SWCNTs@MOF-199 nanocomposite) was characterized with BET, TGA, XRD, EDX and SEM.

\section{Preparation of bare and modified CPEs}

Paraffin oil (as binder) and graphite powder (15:85 wt \%) were mixed with an agate mortar to obtain a carbon paste. The modified carbon pastes were obtained by mixing a certain amount of Pd/SWCNTs@MOF-199 or MOF-199 (as modifiers) with binder and graphite. For preparation of the bare and modified electrodes, the working electrode cavities with $3 \mathrm{~mm}$ diameter were filled with unmodified and modified pastes. For removing any holes and improve the conductivity the pastes were packed on a smooth surface. Before each electrochemical measurement the electrode surface was renewed, polished on a smooth weighing paper, and washed with deionized water.

\section{Results and discussion}

\section{Morphological characterization of Pd/ SWCNTs@MOF-199}

Figure 1 shows the SEM images of the MOF-199 and Pd/ SWCNT@MOF-199. Figure 1a shows that the synthesized MOF-199 has a regular octahedral structure. Figure 1b shows the MOF-199 after modification with Pd/SWCNT, in which the carbon nanotubes on the octahedral shaped MOF-199 is clearly observed.

For a more exact examination, the EDX analysis of Pd/ SWCNT@MOF-199 was also performed. Figure 2 shows
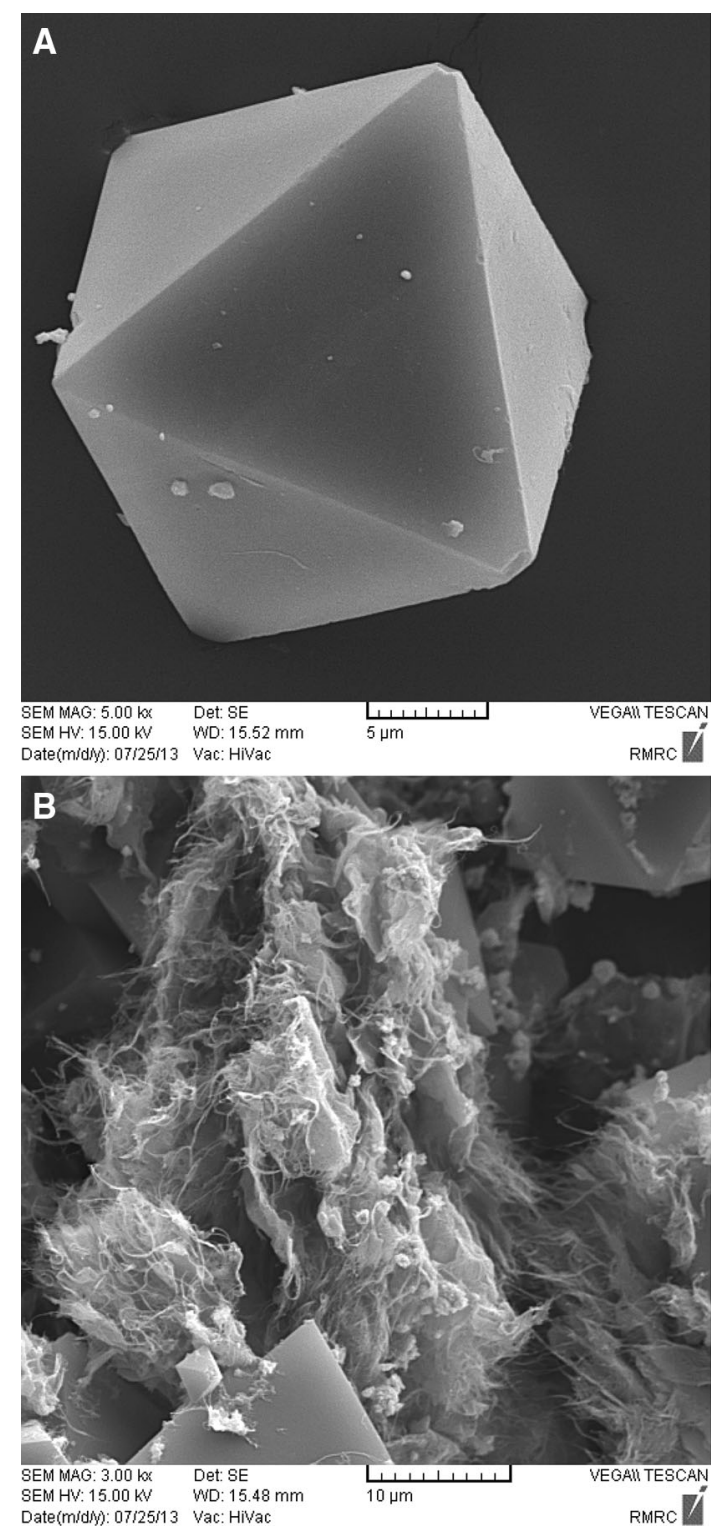

Fig. 1 SEM images of MOF-199 (a), and Pd/SWCNTs@MOF-199 nanocomposite (b)

the EDX analysis for Pd/SWCNT@MOF-199. In this experiment the presence of $\mathrm{Cu}$ and $\mathrm{Pd}$ is confirmed. As shown in this figure, the week peaks observed in the EDX spectrum between 2 and $3 \mathrm{keV}$ are related to $\mathrm{Pd} L_{\alpha}$ and $\mathrm{Pd}$ $L_{\beta}$, which reveals the loaded Pd in the composite is low. In relation to EDX analysis data the $\mathrm{Pd}$ and $\mathrm{Cu} w \mathrm{wt} \%$ are 17.62 and $0.98 \%$, respectively. According to the $\mathrm{Pd}: \mathrm{Cu}$ mole ratio in the feed (about 1:27) and according to EDX analysis (about 1:30) it could be concluded that this ratio is almost constant after composite synthesis. The Au peaks are related to gold coating for the sample preparation before taking SEM images and it is not an impurity in the composite. 
Fig. 2 EDX analysis of the $\mathrm{Pd} /$ SWCNTs@MOF-199

nanocomposite

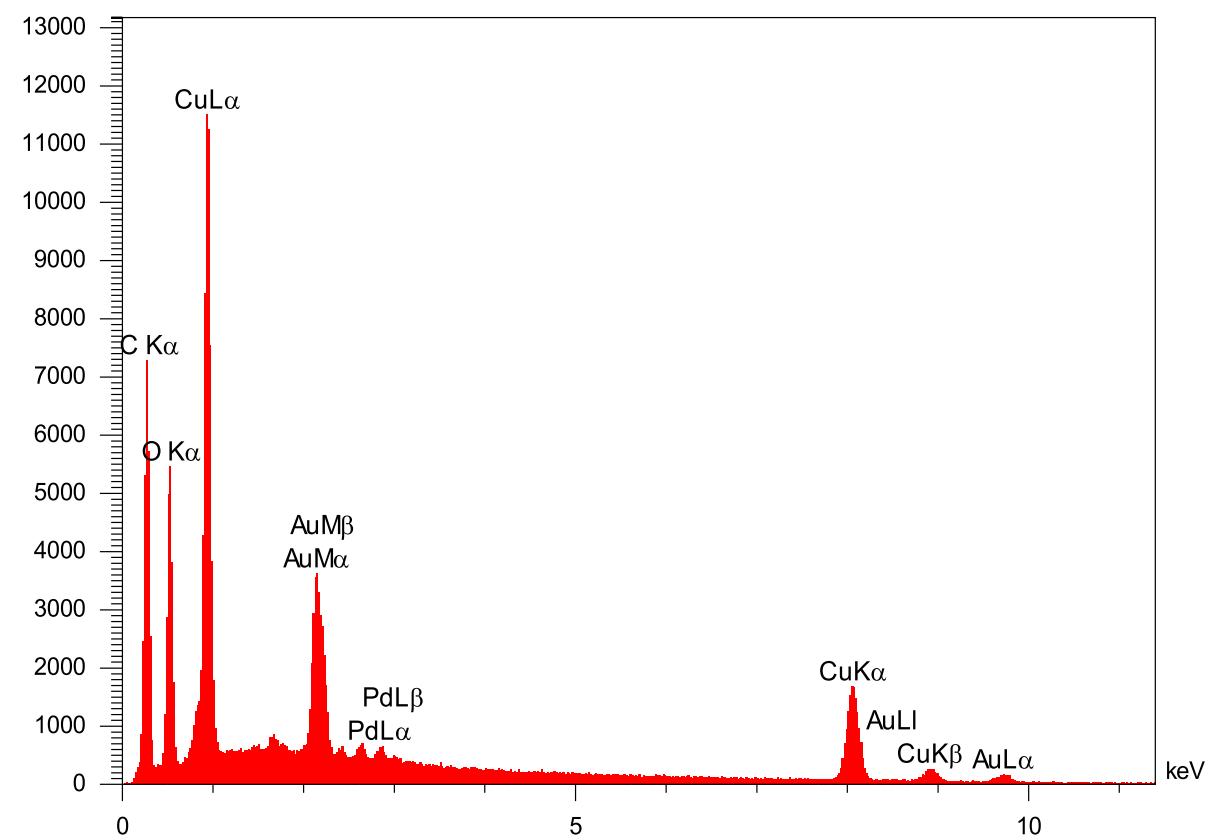

\section{X-ray diffraction (XRD) characterization of nanocomposite}

The X-ray diffraction pattern of the MOF-199 is illustrated in Fig. 3A. The peaks between $10^{\circ}$ and $20^{\circ}$ are related to cubic crystalline structure of MOF-199, which is consistent with previous reports [34]. The peaks at $37^{\circ}$ and $43^{\circ}$ are related to $\mathrm{Cu}_{2} \mathrm{O}$ impurities, but their intensities are very low related to main peaks of the MOF-199, which confirm that the purity of the MOF is reasonable. Figure 3B shows the XRD pattern of the Pd/SWCNT@MOF-199. In this pattern the main peak of $\mathrm{Cu}_{3}(\mathrm{BTC})_{2}$ at $11.68^{\circ}$ corresponds to plane (2 2 2) reflection is not changed after modification, which indicates that the crystal structure of MOF-199 after modification has not changed. The peaks at $40.2^{\circ}$ and $46.5^{\circ}$ with the relative intensity of $10-15 \%$ are related to the reflection of cubic unit cells of Pd.

\section{Thermogravimetric analysis}

Thermal stability of MOF-199 in the air atmosphere was analysed with thermal gravimetric analysis (TGA). Figure 4a illustrates that this compound is stable up to $300{ }^{\circ} \mathrm{C}$. The weight loss is observed in two stages. The first stage $\left(25-240{ }^{\circ} \mathrm{C}\right)$ is related to removal of water molecules from pores, and the solvent molecules trapped in the MOF structure during synthesis. In this stage a $22.15 \%$ weight loss was observed. At the second stage degradation of $\mathrm{OH}$ groups and portion of organic frameworks at $300-350{ }^{\circ} \mathrm{C}$ occurred, which is responsible for a $46.50 \%$ weight loss. Copper oxides are probably the final remaining products at higher temperatures. Figure $4 \mathrm{~b}$ shows the TGA diagram for the Pd/SWCNT@MOF-199. As illustrated in this figure the thermal stability of the composite is slightly better than MOF-199, which may be due to the presence of hydrophobic carbon nanotubes in its structure.

\section{Determination of nitrogen adsorption-desorption isotherms}

Figure 5a shows the $\mathrm{N}_{2}$ adsorption-desorption isotherm of MOF-199, which according to IUPAC classification corresponds to type I isotherm. This isotherm indicates that the available porosity is in micrometer dimensions. Achieving to level off conditions and saturation at relatively low pressures emphasizes that the sample is microporous. At partial pressures near $1 \mathrm{~atm}$ some increase in adsorption is observed, which is related to accumulation of the existing porosities in the framework at relatively high pressures. Initial filling of porosities at low pressures in logarithmic scales represents that the porosities are small and there is an effective interaction between MOF and $\mathrm{N}_{2}$. In addition, negligible hysteresis loop in adsorption/desorption isotherm shows that most of holes are in the microporous range.

Figure $5 \mathrm{~b}$ shows the $\mathrm{N}_{2}$ adsorption-desorption isotherm of Pd/SWCNT@MOF-199. Results show that MOF modification with Pd does not change the microporous structure of MOF, but as expected the surface area is slightly decreased. Table 1 summarizes the results of these experiments.

\section{Electrochemical hydrogen evolution reaction on $\mathrm{Pd} /$ SWCNTs@MOF-199 modified CPE}

Electrochemical studies showed that Pd/SWCNTs@ MOF199 is a good electrocatalyst for HER. Therefore, for 


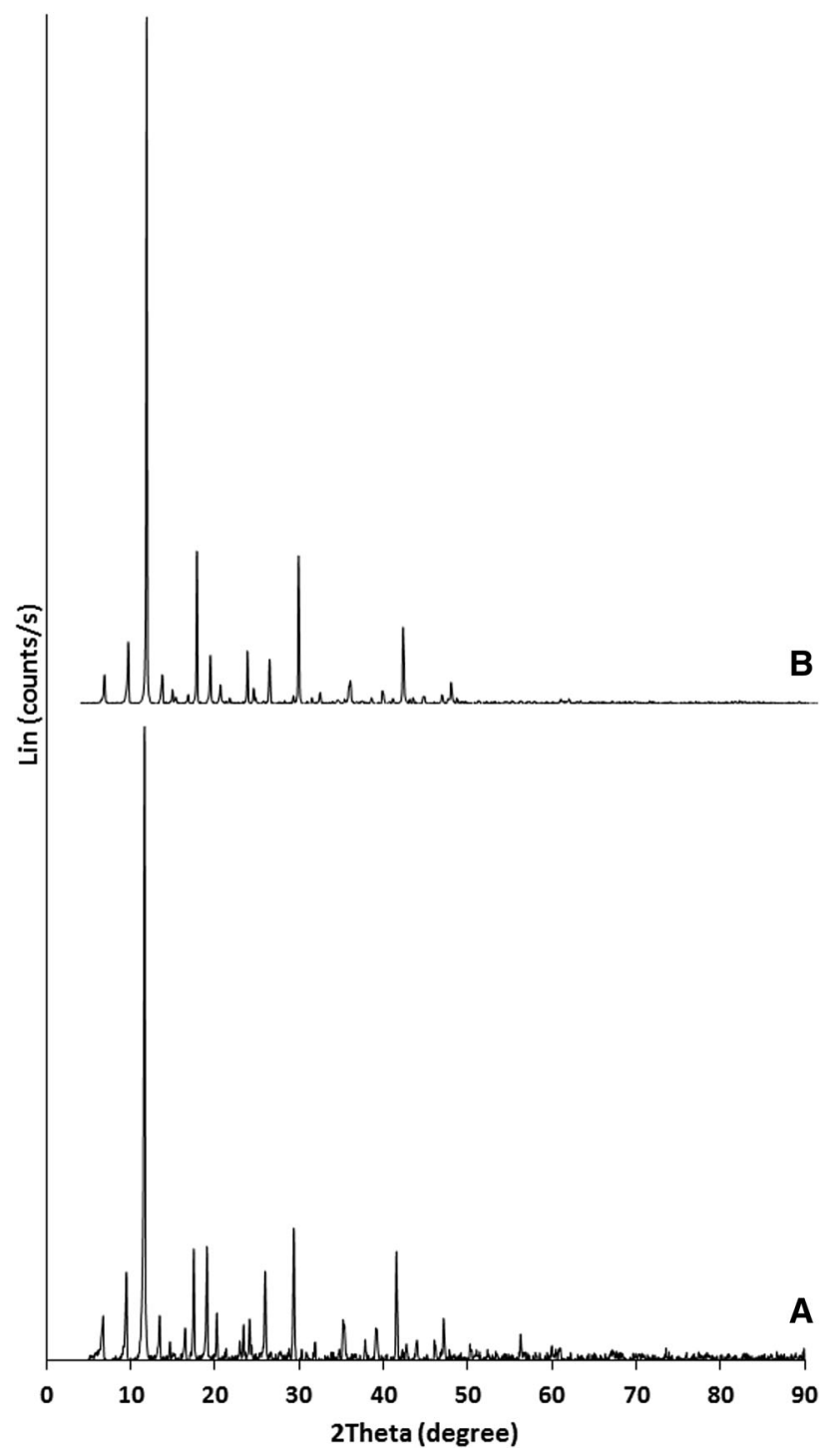

Fig. 3 XRD pattern of MOF-199 (A) and Pd/SWCNT@MOF-199 (B)
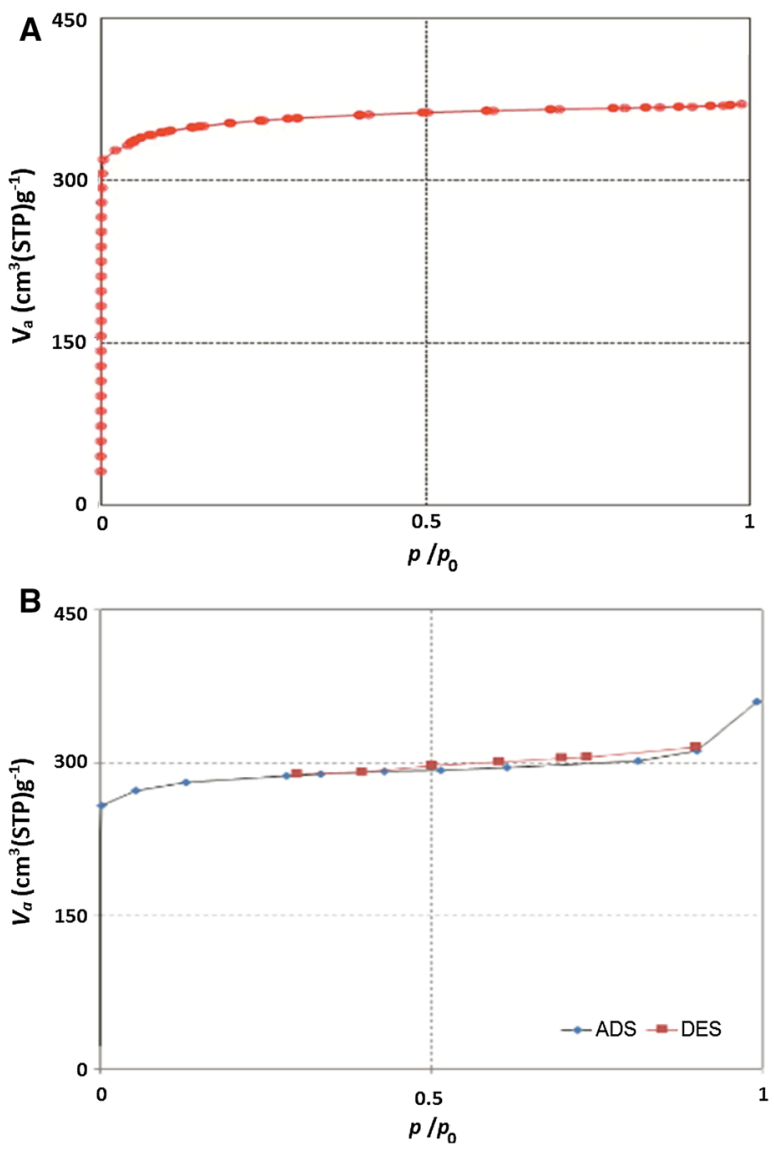

Fig. 5 Adsorption-desorption analysis at $77 \mathrm{~K}$ for MOF-199 (a), and Pd/SWCNT@MOF-199 (b)

Table 1 The structure data of the pores for MOF-199 and Pd/ SWCNT@MOF-199 with adsorption-desorption analysis

\begin{tabular}{llll}
\hline Sample & $\begin{array}{l}V_{\mathrm{p}} \\
\left(\mathrm{cm}^{3} \mathrm{~g}^{-1}\right)\end{array}$ & $\begin{array}{l}d \text { spacing } \\
(\mathrm{nm})\end{array}$ & $\begin{array}{l}A_{\mathrm{BET}} \\
\left(\mathrm{m}^{2} \mathrm{~g}^{-1}\right)\end{array}$ \\
\hline MOF-199 & 0.573 & 1.67 & 1370.0 \\
Pd/SWCNTs@MOF-199 & 0.555 & 1.98 & 1125.8 \\
\hline
\end{tabular}

Fig. 4 TGA thermograms of MOF-199 (solid line), and Pd/ SWCNT@MOF-199 (dashed line)

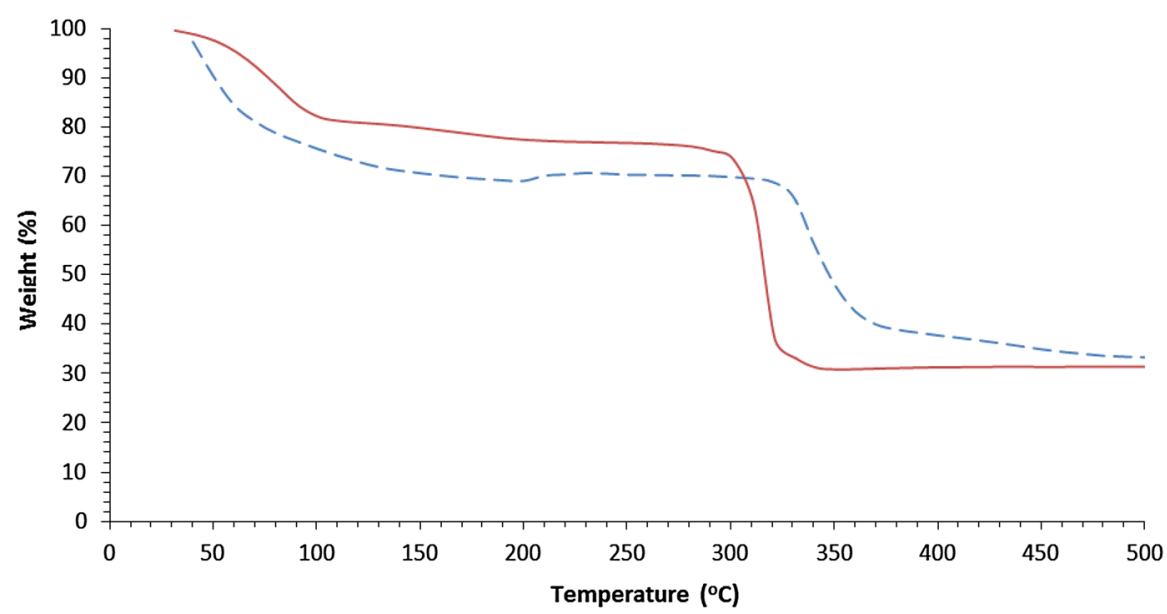


further study, some important parameters including electrocatalyst amounts in the electrode composition, paraffin binder and electrolyte $\mathrm{pH}$ were optimized.

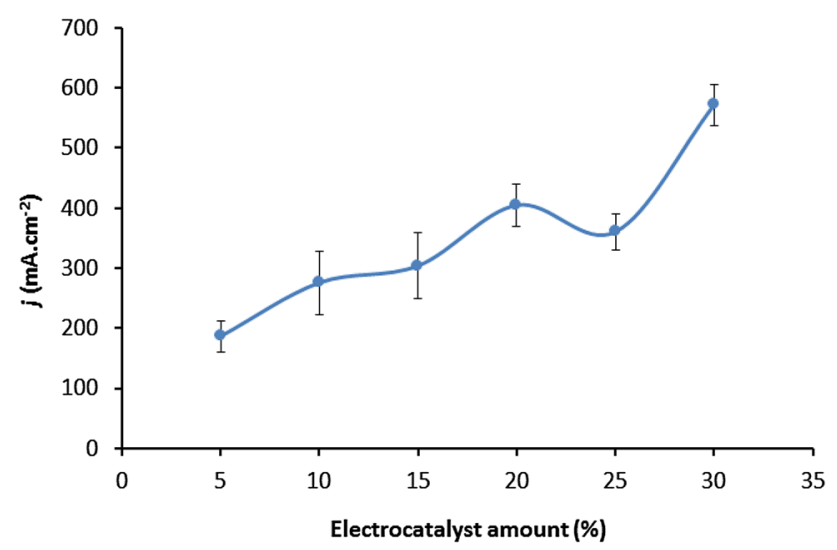

Fig. 6 The effect of catalyst amount on the HER performance. At each composition 20 successive CVs were applied and the $j$ value at the last cycle was measured at $-1 \mathrm{~V}$ (scan rate $100 \mathrm{mV} \mathrm{s}^{-1}, 15 \%$ binder and $2 \mathrm{M}$ sulphuric acid as supporting electrolyte, each point is the average of 3-5 measurements)

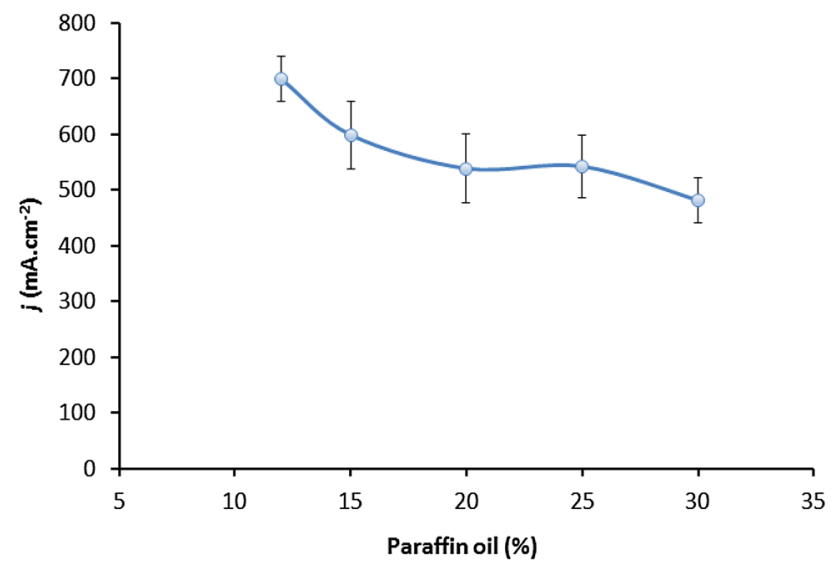

Fig. 7 The effect of oil binder amount on the HER performance. At each composition 20 successive CVs were applied and $\mathrm{j}$ at the last cycle was measured at $-1 \mathrm{~V}$ (scan rate $100 \mathrm{mV} \mathrm{s}^{-1}, 30 \%$ catalyst and $2 \mathrm{M}$ sulphuric acid as supporting electrolyte, each point is the average of 3 or 5 measurements)

\section{The catalyst amount}

For optimization of the catalyst amount, various percentages of Pd/SWCNTs@MOF-199 were added to the paste composition, while the paraffin percent was kept constant at $15 \%$. At these compositions 20 successive cyclic voltammograms (CVs) with the scan rate of $100 \mathrm{mV} \mathrm{s}^{-1}$ at the potential range of 1.2 to $-1 \mathrm{~V}$ were applied on the electrodes in $2 \mathrm{M}$ sulphuric acid solution. At potential of $-1 \mathrm{~V}$ the current density of the HER $(j)$, which could be interpreted as the hydrogen production rate, was measured. The result of this study is summarized in Fig. 6. According to Fig. 6 it is obvious that the $j$ value increasing is a direct consequence of increasing amount of catalyst. However, for catalyst amounts greater than $30 \%$ the paste consolidation decreased, so $30 \%$ was used for the rest of experiments.

\section{Optimization of the paraffin binder amount}

The conductivity and active surface area of the electrode can be affected by the amount of paraffin which is a nonconductive binder. According to this fact, the amount of binder was changed, while the catalyst percentage was kept at $30 \%$ and the electrolyte was $2 \mathrm{M}$ sulphuric acid, and the HER was investigated by applying 20 successive CVs on the electrode surface with the scan rate of $100 \mathrm{mV} \mathrm{s}^{-1}$ in the potential range of 1.2 to $-1 \mathrm{~V}$. Figure 7 illustrates the plot of $j$ at $1 \mathrm{~V}$ vs. paraffin oil percent under the mentioned conditions. Figure 7 clearly demonstrates that when the amount of binder is decreased, it favorably affected on the performance of the HER which can be related to the increase in electrode conductivity. Amounts lower than $12 \%$ were not used, because at these compositions the paste consolidation was very poor.

\section{pH effect}

The effect of $\mathrm{pH}$ on HER efficiency on the $\mathrm{Pd} /$ SWCNTs@MOF-199-CPE was studied in $0.1 \mathrm{M}$
Fig. 8 The effect of supporting electrolyte $\mathrm{pH}$ on the HER performance for Pd/SWCNTs@ MOF-199-CPE. At each solution 20 successive $\mathrm{CVs}$ were applied and $j$ at the last cycle was measured at $-1 \mathrm{~V}$. (scan rate $100 \mathrm{mV} \mathrm{s}^{-1}, 30 \%$ catalyst and $15 \%$ Oil, each point is the average of 3 or 4 measurements)

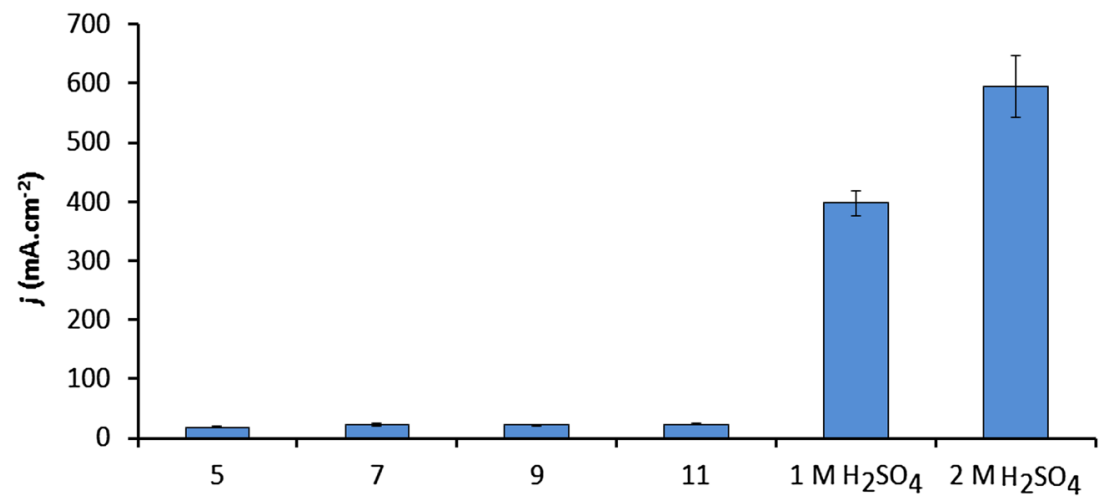




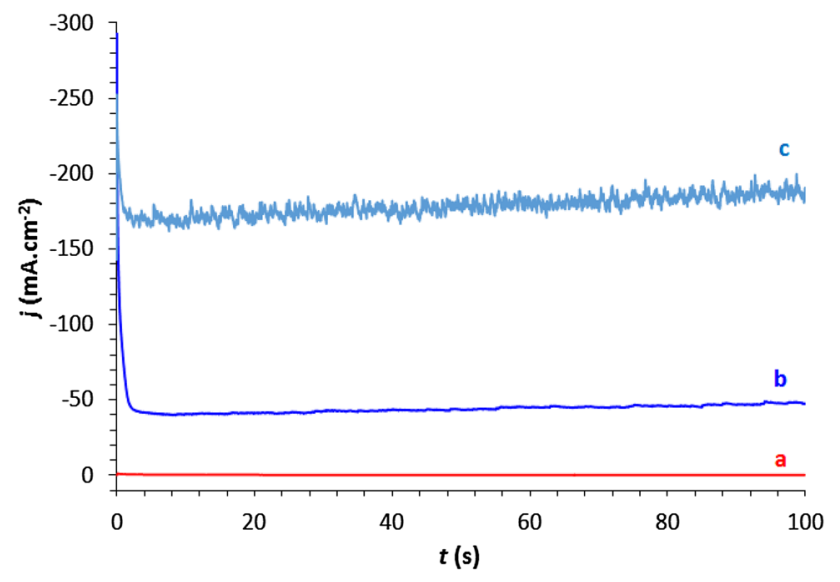

Fig. 9 Chronoamperometry on CPE (a), MOF-199-CPE (b) and Pd/ SWCNTs@MOF-199-CPE (c) in $2 \mathrm{M} \mathrm{H}_{2} \mathrm{SO}_{4}$ with $-0.6 \mathrm{~V}$ applied potential

phosphate buffer $(\mathrm{pH}=5,7,9$ and 11) and 1 and $2 \mathrm{M}$ sulphuric acid solutions. The results of these experiments are illustrated in Fig. 8. By increasing the hydronium concentration, the current of hydrogen production increases, therefore, in this study the largest $j$ was observed in $2 \mathrm{M}$ sulphuric acid solution, so this solution was selected for the rest of experiments. More concentrated sulphuric acid, or other types of strong acids such as $\mathrm{HNO}_{3}$ and $\mathrm{HCl}$ were not used because of their corrosive effects.

\section{Chronoamperometry study}

The electrode response stability was evaluated with chronoamperometry technique. In this experiment a constant potential $(-0.6 \mathrm{~V})$ was applied on CPE, MOF-199CPE and Pd/SWCNTs@MOF-199-CPE under optimal conditions (Fig. 9). According to this figure the highest $j$ for HER is observed for Pd/SWCNTs@MOF-199-CPE. Also the results of modified electrodes show that $j$ does not decrease, but increases with time, and compare to CPE the current densities of HER on modified electrodes are considerably greater.

\section{EIS studies}

In this study before and after applying 20 successive CVs on the CPE, MOF-199-CPE and Pd/SWCNTs@MOF-199$\mathrm{CPE}$, the EIS test was done in $2 \mathrm{M} \mathrm{H}_{2} \mathrm{SO}_{4}$ in the frequency range of $5 \times 10^{-2}$ to $1 \times 10^{5} \mathrm{~Hz}$ and at $-0.25 \mathrm{~V} \mathrm{DC}$ potential. Figure 10 shows that after applying CVs the wave height in the Bode plots, which is related to charge transfer resistance $\left(R_{\mathrm{ct}}\right)$, decreases. This observation confirms that successive CVs improve the rate of electron transfer. This improvement may be due to the activation of SWCNT and graphite surface.
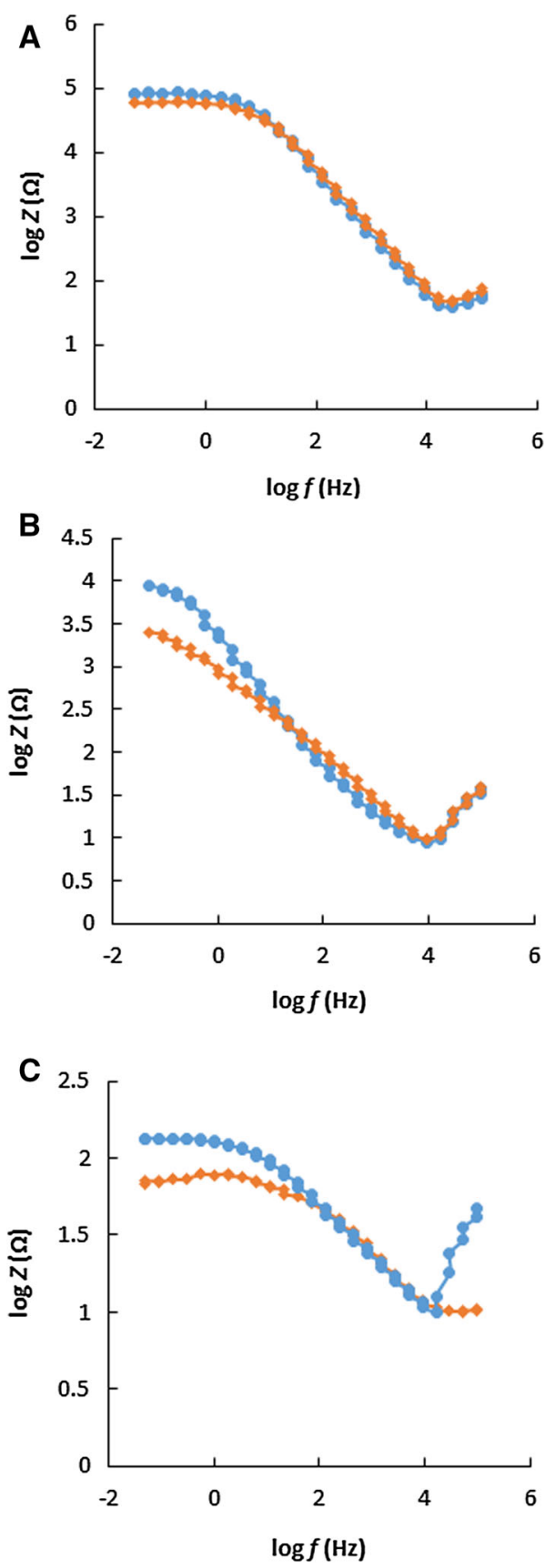

Fig. 10 Bode plots in $0.1 \mathrm{M} \mathrm{KCl}$ containing $10 \mathrm{mM} \mathrm{K}_{3} \mathrm{Fe}(\mathrm{CN})_{6}$ in the frequency range of $5 \times 10^{-2}$ to $1 \times 10^{5} \mathrm{~Hz}$ before (a) and after (b) applying 20 successive CVs in the HER process for CPE (a), MOF-199-CPE (b), and Pd/SWCNTs@MOF-199-CPE (c)

\section{Steady-state polarization curves for HER at bare and modified CPEs}

To evaluate electrocatalytic activities of CPE and modified CPEs, steady-state polarization curves for HER at electrodes were measured by linear sweep voltammetry (LSV) at a very low scan rate $\left(1 \mathrm{mV} \mathrm{s}^{-1}\right)$ (Fig. 11). There is a 


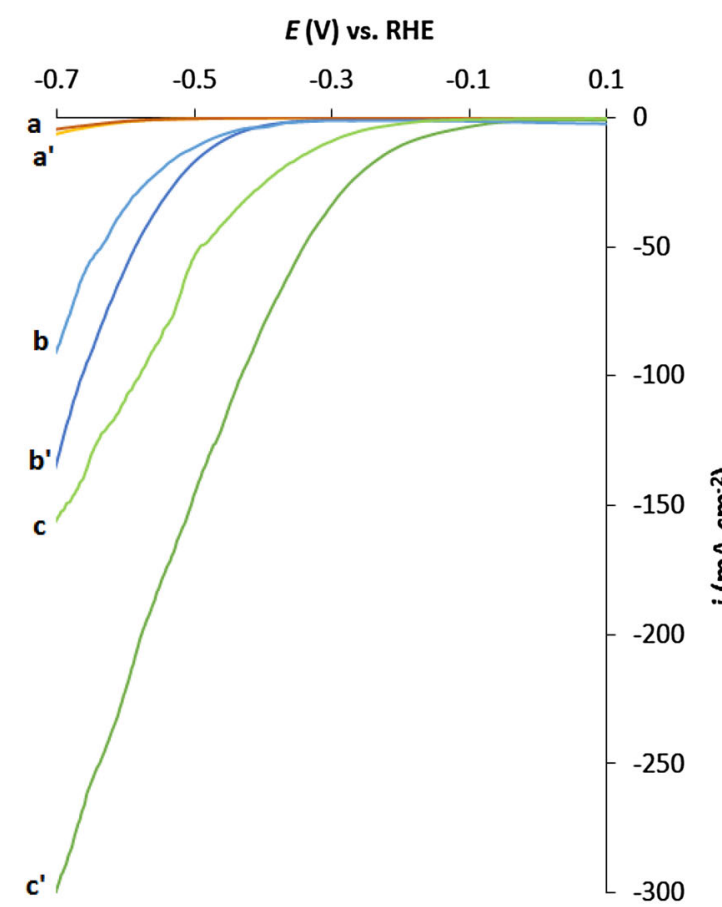

Fig. $11 \mathrm{LSV}$ on CPE $\left(a, a^{\prime}\right)$, MOF-199-CPE $\left(b, b^{\prime}\right)$ and $\mathrm{Pd} /$ SWCNTs@MOF-199-CPE $\left(c, c^{\prime}\right)$ in $2 \mathrm{M} \mathrm{H}_{2} \mathrm{SO}_{4}$ with the scan rate of $1 \mathrm{mV} \mathrm{s}^{-1}$ before and after $\left({ }^{\prime}\right)$ applying 20 successive CVs in $2 \mathrm{M}$

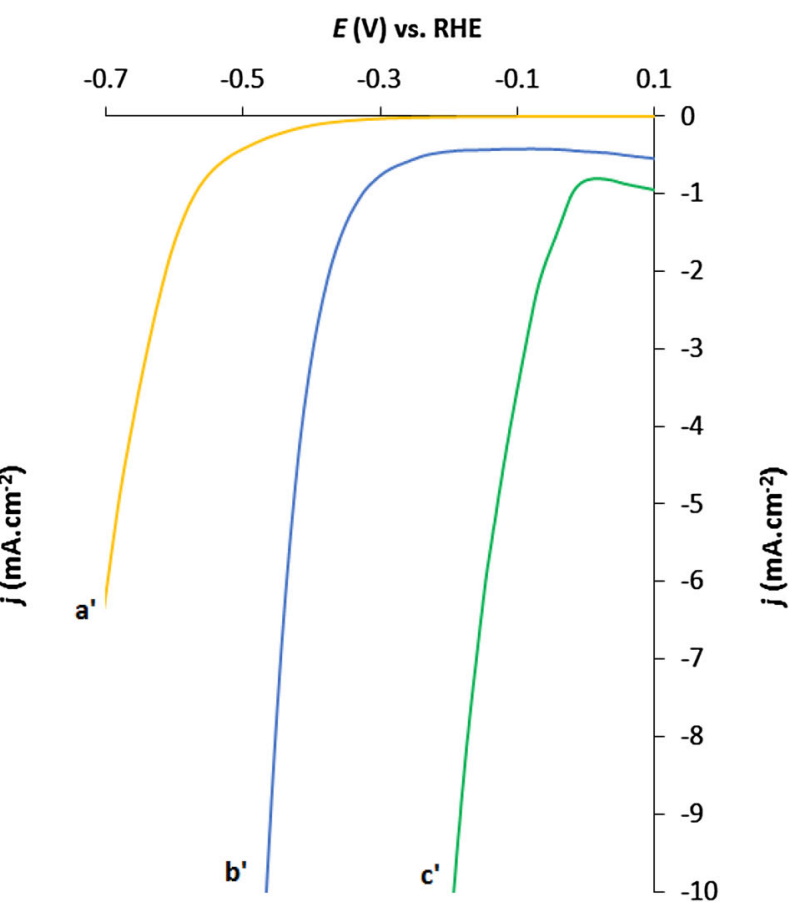

$\mathrm{H}_{2} \mathrm{SO}_{4}$. The right panel is the magnification of the LSVs after applying CVs for better vision of the HER onset potential
Table 2 Tafel slopes $(b)$, exchange current densities $\left(j_{\mathrm{o}}\right)$ and transfer coefficients $(\alpha)$ for HER at CPE, MOF-199-CPE and Pd/SWCNTs@MOF-199CPE

\begin{tabular}{|c|c|c|c|c|c|c|}
\hline \multirow[t]{2}{*}{ Electrode } & \multicolumn{2}{|c|}{$b\left(\mathrm{mV}\right.$ decade $\left.{ }^{-1}\right)$} & \multicolumn{2}{|l|}{$j_{o}\left(\mathrm{~mA} \mathrm{~cm}^{-2}\right)$} & \multicolumn{2}{|l|}{$\alpha$} \\
\hline & Before & After & Before & After & Before & After \\
\hline CPE & 147 & 185 & $6.41 \times 10^{-6}$ & $6.09 \times 10^{-5}$ & 0.40 & 0.32 \\
\hline MOF-199-CPE & 135 & 164 & $9.48 \times 10^{-5}$ & $5.89 \times 10^{-4}$ & 0.36 & 0.44 \\
\hline Pd/SWCNTs@ MOF-199-CPE & 172 & 208 & $9.73 \times 10^{-3}$ & $1.19 \times 10^{-1}$ & 0.34 & 0.28 \\
\hline
\end{tabular}

linear relation between $\eta$ and $\log j$ under steady-state condition and large cathodic overpotential $(\eta)$, (Tafel equation),

$\eta=\frac{2.3 R T}{\alpha F} \log j_{\mathrm{o}}-\frac{2.3 R T}{\alpha F} \log j$ (Tafel equation),

where $R$ is the ideal gas constant $\left(8.314 \mathrm{~J} \mathrm{~mol}^{-1} \mathrm{~K}^{-1}\right), j_{\mathrm{o}}$ is the exchange current density, $T$ is the absolute temperature and $F$ is the Faraday constant. For these three electrodes the values of Tafel slope $(b), j_{\mathrm{o}}$ and transfer coefficient $(\alpha)$ are summarized in Table 2.

The value of $j_{\mathrm{o}}$ increases for all three electrodes after applying CVs, which confirms again that the applied CVs improve the electron transfer rate (or decreases $R_{\mathrm{ct}}$ ). The $j_{\mathrm{o}}$ values are in this order: Pd/SWCNTs@MOF-199$\mathrm{CPE}>\mathrm{MOF}-199-\mathrm{CPE}>\mathrm{CPE}$. In right panel of the Fig. 11, the LSVs after applying CVs are magnified. According to these LSVs it is obvious that the lowest onset potential is for Pd/SWCNTs@MOF-199-CPE (about $0 \mathrm{~V}$ vs. RHE).
The results obtained from polarization and EIS studies both showed that the Pd/SWCNTs@MOF-199-CPE has the best performance related to CPE and MOF-199-CPE. The reason of this observation may be related to the presence of $\mathrm{Pd}$ and SWCNT in the composite structure. There are several reports which have used Pd as a catalyst for electrochemical hydrogen production $[35,36]$, but this metal is expensive, therefore, in this work the loaded Pd on the catalyst is low. Also there are some reports which have used carbon nanotubes in the electrode composition for electrochemical HER [37-39]. In addition, there are several reports which have applied the MOF [22-25], $\mathrm{Pd}$ [40, 41] and SWCNT [37, 38] as adsorbent for hydrogen, and one of the famous mechanisms for electrochemical HER in acidic media is based on hydrogen adsorption on the electrode surface in the rate determining step (Volmer reaction) [42]. Therefore, these materials by improving hydrogen adsorption can facilitate the HER progress.

In comparison with the first report for electrochemical HER with polyoxometalate-based metal organic 
frameworks (POMOFs) [29], although the onset potential is relatively higher, but it seems that the $j$ value for the proposed electrode is greater. Also compared to two recently published reports for electrochemical HER on MOF-5 modified CPE [31] and Ni-based MOF modified GCE [30], the proposed modified CPE electrode has better current densities or onset potential for HER.

\section{Conclusion}

In this study, a nanocomposite of MOF-199 with SWCNT and Pd was synthesized and its characteristics was evaluated by XRD, BET, TGA and SEM. According to the rare reports for application of MOFs in electrochemical hydrogen generation, the performance of this composite as an electrocatalyst in CPE was studied, and some important parameters were optimized. The results show that this modifier has a good performance for HER, which compared to MOF-199 and bare CPE has the best performance. Also electrochemical studies showed that applying successive CVs or a constant potential on the electrodes surface does not decrease the electrode performance, but improves the electrocatalytic properties.

Acknowledgments We gratefully acknowledge the partial support of this work from the Research Council of the Iran University of Science and Technology.

Open Access This article is distributed under the terms of the Creative Commons Attribution 4.0 International License (http://creative commons.org/licenses/by/4.0/), which permits unrestricted use, distribution, and reproduction in any medium, provided you give appropriate credit to the original author(s) and the source, provide a link to the Creative Commons license, and indicate if changes were made.

\section{References}

1. Dincer, I.: Environmental and sustainability aspects of hydrogen and fuel cell systems. Int. J. Energy Res. 31, 29-55 (2007)

2. Momirlan, M., Veziroglu, T.N.: The properties of hydrogen as fuel tomorrow in sustainable energy system for a cleaner planet. Int. J. Hydrogen Energy 30, 795-802 (2005)

3. Liu, B., Li, Z.: A review: hydrogen generation from borohydride hydrolysis reaction. J. Power Sources 187, 527-534 (2009)

4. Naterer, G.F., Suppiah, S., Stolberg, L., Lewis, M., Wang, Z., Daggupati, V., Gabriel, K., Dincer, I., Rosen, M.A., Spekkens, P., Lvov, S.N., Fowler, M., Tremaine, P., Mostaghimi, J., Easton, E.B., Trevani, L., Rizvi, G., Ikeda, B.M., Kaye, M.H., Lu, L., Pioro, I., Smith, W.R., Secnik, E., Jiang, J., Avsec, J.: Canada's program on nuclear hydrogen production and the thermochemical $\mathrm{Cu}-\mathrm{Cl}$ cycle. Int. J. Hydrogen Energy 35, 10905-10926 (2010)

5. Balta, M.T., Dincer, I., Hepbasli, A.: Geothermal-based hydrogen production using thermochemical and hybrid cycles: a review and analysis. Int. J. Energy Res. 34, 757-775 (2010)

6. Shen, S., Guo, L., Chen, X., Ren, F., Mao, S.S.: Effect of $\mathrm{Ag}_{2} \mathrm{~S}$ on solar-driven photocatalytic hydrogen evolution of nanostructured CdS. Int. J. Hydrogen Energy 35, 7110-7115 (2010)
7. Mangrulkar, P.A., Joshi, M.V., Kamble, S.P., Labhsetwar, N.K., Rayalu, S.S.: Hydrogen evolution by a low cost photocatalyst: bauxite residue. Int. J. Hydrogen Energy 35, 10859-10866 (2010)

8. Zhao, W., Wang, Z., Shen, X., Li, J., Xu, C., Gan, Z.: Hydrogen generation via photoelectrocatalytic water splitting using a tungsten trioxide catalyst under visible light irradiation. Int. J. Hydrogen Energy 37, 908-915 (2012)

9. Avasthi, K.S., Reddy, R.N., Patel, S.: Challenges in the production of hydrogen from glycerol-a biodiesel byproduct via steam reforming process. J. Proc. Eng. 51, 423-429 (2013)

10. Khan, Z., Yusup, S., Ahmad, M.M., Rashidi, N.A.: Integrated catalytic adsorption (ICA) steam gasification system for enhanced hydrogen production using palm kernel shell. Int. J. Hydrogen Energy 39, 3286-3293 (2014)

11. Wang, M., Wang, Z., Gong, X., Guo, Z.: The intensification technologies to water electrolysis for hydrogen production-a review. Renew. Sustain. Energy Rev. 29, 573-588 (2014)

12. Yang, J., Cheng, F., Liang, J., Chen, J.: Hydrogen generation by hydrolysis of ammonia borane with a nanoporous cobalt-tungsten-boron-phosphorus catalyst supported on $\mathrm{Ni}$ foam. Int. J. Hydrogen Energy 36, 1411-1417 (2011)

13. Raoof, J.B., Ojani, R., Esfeden, S.A., Nadimi, S.R.: Fabrication of bimetallic $\mathrm{Cu} / \mathrm{Pt}$ nanoparticles modified glassy carbon electrode and its catalytic activity toward hydrogen evolution reaction. Int. J. Hydrogen Energy 35, 3937-3944 (2011)

14. Ghaffarinejad, A., Sadeghi, N., Kazemi, H., Khajehzadeh, A., Amiri, M., Noori, A.: Effect of metal hexacyanoferrate films on hydrogen evolution reaction. J. Electroanal. Chem. 685, 103-108 (2012)

15. Ghaffarinejad, A., Magsoudi, E., Sadeghi, N.: Hydrogen generation by shimalite Ni catalyst. Anal. Bioanal. Chem. 5, 316-324 (2013)

16. Safavi, A., Kazemi, H., Kazemi, S.H.: In situ electrodeposition of graphene/nano-palladium on carbon cloth for electrooxidation of methanol in alkaline media. J. Power Sources 256, 354-360 (2014)

17. Klein, N., Senkovska, I., Gedrich, K., Stoeck, U., Henschel, A., Mueller, U., Kaskel, S.: A mesoporous metal-organic framework. Angew. Chem. Int. Ed. 48, 9954-9957 (2009)

18. O'Keeffe, M., Eddaoudi, M., Li, H., Reineke, T., Yaghi, O.M.: Frameworks for extended solids: geometrical design principles. J. Solid State Chem. 152, 3-20 (2000)

19. Hoskins, B., Robson, R.: Design and construction of a new class of scaffolding-like materials comprising infinite polymeric frameworks of 3D-linked molecular rods. A reappraisal of the zinc cyanide and cadmium cyanide structures and the synthesis and structure of the diamond-related frameworks $\left[\mathrm{N}\left(\mathrm{CH}_{3}\right)_{4}\right][-$ $\left.\mathrm{Cu}^{\mathrm{I}} \mathrm{Zn}^{\mathrm{II}}(\mathrm{CN})_{4}\right]$ and $\mathrm{Cu}^{\mathrm{I}}\left[4,4^{\prime}, 4^{\prime \prime}, 4^{\prime \prime \prime}\right.$-tetracyanotetraphenylmethane] $\mathrm{BF}_{4} \cdot \mathrm{xC}_{6} \mathrm{H}_{5}$ N. J. Am. Chem. Soc. 112, 1546-1554 (1990)

20. Oh, M., Mirkin, C.A.: Chemically tailorable colloidal particles from infinite coordination polymers. Nature 438, 651-654 (2005)

21. Lee, J., Farha, O.K., Roberts, J., Scheidt, K.A., Nguyen, S.T., Hupp, J.T.: Metal-organic framework materials as catalysts. Chem. Soc. Rev. 38, 1450-1459 (2009)

22. Rowsell, J.L., Yaghi, O.M.: Strategies for hydrogen storage in metal-organic frameworks. Angew. Chem. Int. Ed. 44, 4670-4679 (2005)

23. Murray, L.J., Dincă, M., Long, J.R.: Hydrogen storage in metalorganic frameworks. Chem. Soc. Rev. 38, 1294-1314 (2009)

24. Moellmer, J., Moeller, A., Dreisbach, F., Glaeser, R., Staudt, R.: High pressure adsorption of hydrogen, nitrogen, carbon dioxide and methane on the metal-organic framework HKUST-1. J. Microporous Mesoporous Mat. 138, 140-148 (2011)

25. Lim, D.W., Chyun, S.A., Suh, M.P.: Hydrogen storage in a potassium-ion-bound metal-organic framework incorporating 
crown ether struts as specific cation binding sites. Angew. Chem. Int. Ed. 53, 7819-7822 (2014)

26. Wen, M., Mori, K., Kamegawa, T., Yamashita, H.: Aminefunctionalized MIL-101 (Cr) with imbedded platinum nanoparticles as a durable photocatalyst for hydrogen production from water. Chem. Commun. 50, 11645-11648 (2014)

27. Toyao, T., Saito, M., Dohshi, S., Mochizuki, K., Iwata, M., Higashimura, H., Horiuchi, Y., Matsuoka, M.: Development of a $\mathrm{Ru}$ complex-incorporated MOF photocatalyst for hydrogen production under visible-light irradiation. Chem. Commun. 50, 6779-6781 (2014)

28. He, J., Wang, J., Chen, Y., Zhang, J., Duan, D., Wang, Y., Yan, Z.: A dye-sensitized Pt@ UiO-66 (Zr) metal-organic framework for visible-light photocatalytic hydrogen production. Chem. Commun. 50, 7063-7066 (2014)

29. Nohra, B., El Moll, H., Rodriguez Albelo, L.M., Mialane, P., Marrot, J., Mellot-Draznieks, C., O'Keeffe, M., Ngo Biboum, R., Lemaire, J., Keita, B., Nadjo, L., Dolbecq, A.: Polyoxometalatebased metal organic frameworks (POMOFs): structural trends, energetics, and high electrocatalytic efficiency for hydrogen evolution reaction. J. Am. Chem. Soc. 133, 13363-13374 (2011)

30. Tian, T., Ai, L., Jiang, J.: Metal-organic framework-derived nickel phosphides as efficient electrocatalysts toward sustainable hydrogen generation from water splitting. RSC Adv. 5, 10290-10295 (2015)

31. Yang, H.M., Song, X.L., Yang, T.L., Liang, Z.H., Fan, C.M., Hao, X.G.: Electrochemical synthesis of flower shaped morphology MOFs in an ionic liquid system and their electrocatalytic application to the hydrogen evolution reaction. RSC Adv. 4, $15720-15726$ (2014)

32. Xiang, Z., Cao, D., Shao, X., Wang, W., Zhang, J., Wu, W.: Facile preparation of high-capacity hydrogen storage metal-organic frameworks: a combination of microwave-assisted solvothermal synthesis and supercritical activation. Chem. Eng. Sci. 65, 3140-3146 (2010)

33. Yang, S.J., Choi, J.Y., Chae, H.K., Cho, J.H., Nahm, K.S., Park, C.R.: Preparation and enhanced hydrostability and hydrogen storage capacity of CNT@ MOF-5 hybrid composite. Chem. Mater. 21, 1893-1897 (2009)

34. Loera-Serna, S., Oliver-Tolentino, M.A., de Lourdes LópezNúñez, M., Santana-Cruz, A., Guzmán-Vargas, A., CabreraSierra, R., Beltrán, H.I., Flores, J.: Electrochemical behavior of [Cu3(BTC)2] metal-organic framework. The effect of the method of synthesis. J. Alloy. Compd. 540, 113-120 (2012)

35. Searson, P.C.: Hydrogen evolution and entry in palladium at high current density. J. Acta Metal. Mater. 39, 2519-2525 (1991)

36. Safavi, A., Kazemi, S.H., Kazemi, H.: Electrocatalytic behaviors of silver-palladium nanoalloys modified carbon ionic liquid electrode towards hydrogen evolution reaction. J. Fuel 118, 156-162 (2014)

37. Fernandez, P., Castro, E., Real, S., Martins, M.: Electrochemical behavior of single walled carbon nanotubes-hydrogen storage and hydrogen evolution reaction. Int. J. Hydrogen Energy 34, 8115-8126 (2009)

38. Prosini, P.P., Pozio, A., Botti, S., Ciardi, R.: Electrochemical studies of hydrogen evolution, storage and oxidation on carbon nanotube electrodes. J. Power Sources 118, 265-269 (2013)

39. Paunović, P., Dimitrov, A.T., Popovski, O., Slavcheva, E., Grozdanov, A., Lefterova, E., Petruševski, G., Jordanov, S.H.: Effect of activation/purification of multiwalled carbon nanotubes (MWCNTs) on the activity of non-platinum based hypo-hyper d-electrocatalysts for hydrogen evolution. J. Mater. Res. Bull 44, 1816-1821 (2009)

40. Conrad, H., Ertl, G., Latta, E.E.: Adsorption of hydrogen on palladium single crystal surfaces. Surf. Sci. 41, 435-446 (1974)

41. Lopez, M.J., Cabria, I., Alonso, J.A.: Palladium clusters anchored on graphene vacancies and their effect on the reversible adsorption of hydrogen. J. Phys. Chem. C 118, 5081-5090 (2014)

42. Abbaspour, A., Mirahmadi, E.: Electrocatalytic hydrogen evolution reaction on carbon paste electrode modified with $\mathrm{Ni}$ ferrite nanoparticles. J. Fuel 104, 575-582 (2013) 